\title{
Violência contra a mulher: análise de casos atendidos em serviço de atenção à mulher em município do Sul do Brasil
}

\section{Violence against women: analysis of cases attended in a women care centre in a municipality in Southern Brazil}

\author{
Elaine Ferreira Galvão \\ Especialista em Saúde Coletiva, Socióloga. Secretaria Municipal \\ da Mulher, Prefeitura Municipal de Londrina. \\ E-mail: elainegalvao®uol.com.br \\ Selma Maffei de Andrade \\ Doutora em Saúde Pública, Professora Adjunta, Departamento \\ de Saúde Coletiva, Centro de Ciências da Saúde, Universidade \\ Estadual de Londrina. \\ E-mail: semaffeiळsercomtel.com.br
}

\section{Resumo}

Este artigo, de caráter descritivo, tem como objetivo apresentar o perfil de mulheres atendidas em um centro de atendimento à mulher em Londrina, Paraná, e caracterizar os casos quanto aos tipos de violência sofrida, queixa principal, ambiente em que ocorreu a violência e tipo de vínculo do agressor com a mulher. Utilizando-se o Programa Epi Info 6.04 montou-se um banco de dados com as informações extraídas das fichas das mulheres atendidas pelo Serviço, no ano de 2001. Do total de 470 fichas analisadas, verificou-se que a média de idade das mulheres é de 34 anos. A maioria, $47,2 \%$, declarou-se casada e $54 \%$ possuem um ou dois filhos. Declararam-se chefes de família 38,7\% das mulheres. A violência emocional prevaleceu, representando $56,4 \%$ dos casos, seguida pela violência física (32,1\%). Os principais agressores são os atuais maridos ou companheiros das mulheres $(73,4 \%)$ e o lar é o espaço onde a maioria das agressões ocorre. Considerando-se a complexidade do problema, que está associado à questão da construção social dos papéis masculinos e femininos e da desigualdade existente nas relações entre os gêneros, conclui-se que os serviços de atendimento às mulheres em situação de violência são de fundamental importância e que estes devem estar articulados com os serviços de saúde no desenvolvimento de ações preventivas e na perspectiva da atenção integral à mulher.

Palavras-chave: Violência; Mulheres maltratadas; Violência doméstica; Saúde da mulher. 
Abstract

The objective of this descriptive study is to present the profile of women who were assisted at a women's care center in Londrina, Paraná State, Brazil, and to characterize the cases in relation to types of violence, main complain, environment where the violence occurred and the woman-perpetrator relationship. Information extracted from the records of women assisted in 2001 was processed using the Epi Info software, version 6.04. Of a total of 470 records analyzed, the mean age of the women was 34 . The majority $(47.2 \%)$ reported to be married, $54 \%$ had one or two children and $38.7 \%$ declared to be responsible for their families. Emotional abuse was the main form of violence ( $56.4 \%)$, followed by physical violence $(32.1 \%)$. The main perpetrators of violence against women were their own current husband or intimate partner (73.4\%) and their house was the space where the majority of episodes of violence occurred. Given the complexity of the problem, which is associated to the social construction of the roles of men and women in the society and to the inequality in gender relations, it can be concluded that the provision of services to attend women who are victimized by violence is of vital importance and that these services should be articulated with health services in the development of preventive actions in order to provide comprehensive care to women.

Key Words: Violence; Battered Women; Domestic Violence; Women's Health

\section{Introdução}

0 presente artigo é resultado de uma pesquisa que teve como objeto de estudo os casos de violência contra a mulher registrados no Centro de Atendimento à $\mathrm{Mu}$ lher (CAM), da Prefeitura de Londrina, Paraná, no período de janeiro a dezembro de 2001. O objetivo da pesquisa foi traçar o perfil das mulheres atendidas no CAM e caracterizar os casos quanto aos serviços que os encaminharam, tipos de violência sofrida, queixa principal, ambiente em que ocorreu a violência, tipo de vínculo do agressor e tempo vivido em situação de violência.

Pesquisas têm apontado a violência contra a mulher como um fenômeno que atinge diversas sociedades, podendo variar nas formas em que é praticada (Saffioti; Almeida, 1995). O reconhecimento da gravidade do problema vem fazendo com que, em muitos países, medidas de prevenção e controle sejam tomadas.

No Brasil, durante toda a década de 1980, o movimento feminista desenvolveu uma série de ações que deram visibilidade à questão, visando trazer para a esfera pública um assunto que até então era visto como de âmbito privado. Como resultado dessa atuação, a violência contra a mulher começou a ser tratada como problema a ser combatido por meio de políticas públicas. Serviços especializados foram criados, sobretudo nas grandes cidades, como as delegacias da mulher, os centros de atendimento jurídico e de apoio social às mulheres em situação de violência, e as casas abrigo (Camargo, 200o).

Também na década de 1980, a violência contra a mulher foi reconhecida pela Organização Mundial da Saúde (OMS) como um problema de saúde pública, pela sua dimensão e pela gravidade das seqüelas orgânicas e emocionais que produz (Alves; Coura Filho, 2001). Durante essa década, o tema ganhou espaço também no meio acadêmico, resultando em certa proliferação de estudos e pesquisas que vieram contribuir para uma melhor apreensão de sua extensão e compreensão de sua dinâmica.

Enfocando o tema numa perspectiva econômica, uma nova abordagem foi promovida pelo Banco Mundial que, no ano de 1998, contabilizou os custos da violência doméstica, divulgando que um em cada cinco dias de absenteísmo no trabalho, por parte de mulheres, resulta da violência que essas sofrem dentro de casa (Santana, 1999). 
Segundo Saffioti e Almeida (1995), os dados mundiais revelam que a violência contra a mulher é praticada em diferentes países, atingindo grande parte da população feminina, tanto adulta quanto infantil, numa dimensão que nos permite afirmar que o problema apresenta um caráter endêmico. A violência contra a mulher pode se manifestar de diferentes formas e nos mais diversos espaços da sociedade, independentemente da classe social, da idade, da raça/ etnia, do tipo de cultura ou do grau de desenvolvimento econômico do país (Organização Mundial da Saúde, 2002).

Inúmeras pesquisas demonstram que é no espaço doméstico onde a maior parte das agressões contra mulheres ocorre. Segundo Barsted (1998), isto acontece graças à cumplicidade e indiferença da sociedade para com a violência que ocorre no interior da família, que, muitas vezes, acaba por se constituir em um espaço de arbítrio e de violência. Assim, a violência doméstica é legitimada por uma ordem patriarcal de organização familiar, na qual a dominação masculina é vista como natural (Diniz e cols., 1999). Essa naturalização e privatização da violência dificultam uma atitude de resistência e ruptura, por parte da mulher, com a situação vivenciada. A superação da violência implica uma revisão de valores, crenças e atitudes socialmente estabelecidas.

Neste sentido, a violência contra a mulher deve ser analisada dentro do contexto das relações sociais de gênero. De acordo com Grossi (1996, p. 135), “Ao destinar para a mulher um papel submisso e passivo, a sociedade cria espaço para a dominação masculina, onde o processo de mutilação feminina é lento, gradual e considerado legítimo." Nesse processo, a violência constitui-se em um dos mecanismos de dominação do homem sobre a mulher, legitimado por instituições como a família e o casamento.

Levantamento do Instituto Brasileiro de Geografia e Estatística (IBGE), realizado no final da década de 1980, mostrou que, no Brasil, as mulheres eram $63 \%$ das pessoas que sofriam agressões físicas no espaço doméstico (Fontana; Santos, 2001). Segundo Grossi (1996), dados referentes aos casos de violência contra a mulher, denunciados nas delegacias brasileiras, demonstram que 70\% das agressões ocorrem dentro de casa, sendo praticadas por maridos ou companheiros.
Em Londrina, a Delegacia da Mulher registrou, desde a sua criação, em agosto de 1986, até julho de 1998, um total de 19.788 boletins de ocorrência, dos quais 10\% resultaram em inquérito. No ano de 1999 , essa delegacia registrou 1849 boletins de ocorrência, sendo $43 \%$ relativos a lesão corporal e $41 \%$ a ameaças. No mesmo ano, do total de 1461 mulheres atendidas pelo Instituto Médico Legal de Londrina, 755 foram agredidas fisicamente, correspondendo a $78 \%$ dos casos; 64 sofreram estupro, correspondendo a $6,25 \%$ dos casos e 25 denunciaram atos libidinosos, representando 2,6\% dos atendimentos (Prefeitura Municipal de Londrina, 2000).

Alguns estudos chamam a atenção para os impactos da violência à saúde física e mental das mulheres (Grossi, 1996; Diniz e cols., 1999; Klevens, 2001; Schraiber e cols., 2002). Na opinião de Camargo (2000), a Organização Panamericana de Saúde (OPAS) trouxe uma grande contribuição para essa discussão quando reconheceu, em seu relatório Las Condiciones de Salud em las Américas, de 1991, que a violência é uma importante causa de adoecimento das mulheres.

De acordo com Grossi (1996), mulheres que sofrem violência doméstica estão cinco vezes mais predispostas a apresentarem problemas psicológicos em relação às mulheres que não vivenciam essa situação. Alterações como nervosismo, esquecimento, sentimento de insegurança e transtornos do sono, foram relatadas por mulheres que sofreram violência (Guerra, 1997). Segundo Diniz e cols. (1999), as mulheres em situação de violência estão ainda mais vulneráveis a abortos, violação sexual e doenças sexualmente transmissíveis (DSTs). Muitas vezes, submetidas a relações sexuais forçadas, não se sentem encorajadas a exigir dos parceiros o uso de métodos contraceptivos e de proteção contra as DSTs. Essas dificuldades estão relacionadas às questões de poder legitimadas pela sociedade, constituindo um obstáculo por muitos considerado intransponível (Diniz e cols., 1999, p. 108).

Estudiosos e profissionais que atuam na área de atendimento às mulheres em situação de violência estimam que os dados não refletem a magnitude do problema e que o número de casos não notificados seja muito grande (Guerra, 2000; Vaccari, 2001). Fatores como medo do agressor e vergonha da família e da sociedade fazem com que muitas mulheres deixem de denunciar seus agressores (Lemes, 2002) e, quando o fazem, mui- 
tas desistem de levar a denúncia adiante (Schraiber e D'Oliveira,1999). Por outro lado, como destacam Schraiber e cols. (2003), muitas mulheres agredidas não reconhecem a situação vivida como violência.

Não obstante a sub-notificação dos casos de violência contra a mulher, estimada pelos profissionais da área, os estudos e pesquisas que vêm sendo desenvolvidos nos últimos anos têm contribuído para dar visibilidade ao problema (Deslandes e cos., 2000; Alves; Coura Filho, 2001; Schraiber e cols., 2002), o que vem resultando na proliferação de diversos serviços especializados no atendimento à mulher em situação de violência. Nesse contexto, Londrina se insere como uma cidade privilegiada, contando com três serviços especializados: a Delegacia da Mulher, criada no ano de 1986, o CAM, criado em 1993, e o Programa Rosa Viva, de atendimento e tratamento das mulheres que sofrem violência sexual, inaugurado em outubro de 2001. A importância dos serviços especializados no atendimento a mulheres que vivem em situação de violência é, hoje, reconhecida por diversos setores da sociedade e sua manutenção defendida pelas organizações do movimento de mulheres.

Considerando a complexidade da questão, que deve ser analisada do ponto de vista das desigualdades de poder nas relações entre os gêneros, coloca-se ainda como um desafio para as políticas públicas, nessa área, o desenvolvimento de ações de prevenção e combate dessa forma de violência. A experiência de atendimento acumulada pelos serviços acima citados constitui-se numa importante fonte de informações para estudos e análise do problema. Por meio do presente estudo pretende-se melhor conhecer a realidade das mulheres atendidas no CAM. Com isso esperase contribuir para a definição de novas estratégias de atuação nessa área, melhorando a estrutura de serviços e implementando ações de combate e prevenção da violência contra a mulher.

\section{Material e Métodos}

Este estudo, de caráter quantitativo e descritivo, foi desenvolvido no Centro de Atendimento à Mulher (CAM), que é um programa da Secretaria Municipal da Mulher da Prefeitura do Município de Londrina. Implantado em abril de 1993, o Serviço oferece atendimento jurídico, social e psicológico a mulheres que sofrem violência física, emocional, sexual e social.

O CAM está organizado em quatro setores de atendimento: encaminhamento, psicologia, social e jurídico. No setor de encaminhamento as mulheres recebem um atendimento inicial durante o qual é feito um breve diagnóstico para levantar suas queixas e demandas, procedendo-se, a partir desse levantamento, ao encaminhamento para os demais setores do CAM ou para outros serviços, quando for o caso, como: Delegacia da Mulher, Conselho Tutelar, Fórum, Unidades Básicas de Saúde e outros, para atendimento complementar ou como encaminhamento definitivo, quando o caso não se enquadra nos critérios de atendimento do CAM. $\mathrm{O}$ atendimento no setor de psicologia pode ser tanto individual quanto em grupo, por meio de aconselhamento, orientação e apoio nas situações de conflito. $\mathrm{O}$ setor de serviço social presta atendimento individual ou em grupo, e familiar, realizando investigação social para os processos jurídicos e psicológicos, visitas domiciliares, orientação, encaminhamento aos recursos sociais da comunidade e acompanhamento (Prefeitura do Município de Londrina, 200o).

De abril de 1993 a dezembro de 2001, o CAM prestou atendimento a 5757 mulheres, apresentando uma média de 52 novos casos mensais. 0 público priorizado é de mulheres com renda mensal de até três salários mínimos e que se encontram em situação de violência. Porém, todas as mulheres que procuram o serviço, independentemente de sua condição social, passam pelo setor de encaminhamento e, no caso de não se enquadrarem nos critérios acima, são orientadas sobre seus direitos e encaminhadas para outros serviços que ofereçam o atendimento solicitado.

Em casos excepcionais, como assédio sexual, que se trata de um tema relativamente novo no âmbito da violência de gênero e também ainda muito polêmico, e em casos de mulheres que desejam realizar o aborto legal, o CAM tem prestado atendimento, independentemente da condição sócio-econômica da mulher.

Para caracterizar os tipos de violência apresentados pelas mulheres que procuram o serviço, os profissionais do CAM elaboraram uma classificação tendo como foco central a adequação à legislação pertinente, com o objetivo de melhor caracterizar as agressões do ponto de vista legal. Assim, o serviço utiliza a seguinte classificação: violência sexual, cujas queixas principais são: atentado violento ao pudor, sedução, 
estupro, rapto, atos libidinosos, assédio sexual e incesto; violência física, que corresponde às queixas de lesão corporal, homicídio, cárcere privado, abandono material e ameaça à integridade física; violência emocional, que compreende queixas como tortura psicológica, ameaça verbal, indução ao suicídio, constrangimento ilegal, infidelidade ou adultério, negação de paternidade e atos destrutivos; violência moral, quando se trata de calúnia, difamação ou injúria; violência social, cujas queixas principais são a discriminação de gênero, a discriminação ideológica, a discriminação racial e a discriminação por idade ou condição física.

Embora não exista consenso em torno da classificação dos tipos de violência contra a mulher, em geral os serviços de atenção à mulher e pesquisadores da área os classificam em violência física, sexual e emocional ou psicológica (Centers for Disease Control and Prevention, 2000; Lemes, 2002; Schraiber e cols., 2003). No CAM também se utiliza o conceito de violência moral, que corresponde às agressões relacionadas à noção de ofensa à honra, e de violência social, que compreende as discriminações. No presente estudo, decidiu-se utilizar a classificação utilizada pelo próprio serviço, por se tratar de uma investigação com dados do serviço.

Para este estudo foram utilizadas as fichas individuais das usuárias do CAM, nas quais constam dados pessoais da mulher agredida, informações sobre tipo de violência sofrida, ambiente em que ocorreu a violência, tipo de vínculo do agressor com a mulher, entre outras. 0 estudo foi conduzido em 2002, sendo, portanto, analisadas as fichas das mulheres atendidas no último ano completo disponível (de janeiro a dezembro de 2001), totalizando 473 fichas. Destas, foram excluídas três, por não se tratar de casos de violência, mas de pedido de orientação e apoio na garantia de direitos.

Para a coleta dos dados, obteve-se previamente o consentimento da coordenação do CAM e o projeto foi aprovado pelo Comitê de Ética em Pesquisa da Universidade Estadual de Londrina.

Utilizando-se o Programa Epi Info 6.04 montouse um banco de dados, no qual foram processados os seguintes dados: nome da usuária, estado civil, situação de trabalho, setor de atividade e função desempenhada, renda individual, chefia da família, escolaridade, número de filhos, idade dos filhos, queixa prin- cipal, tipo de violência, ambiente onde ocorreu a violência, o período de tempo em que a mulher sofria violência, se era a primeira denúncia, quem era o agressor e por quem a usuária havia sido encaminhada. As informações foram analisadas por meio da verificação de freqüências.

\section{Resultados e Discussão}

Conforme mostra a tabela 1, a faixa etária que predominou entre as mulheres atendidas no CAM, em 2001, foi a de 30 a 39 anos, seguida da faixa etária de 20 a 29 anos, sendo que a média de idade foi de 34 anos, com desvio padrão de 11 anos. Com relação ao estado civil, $47,2 \%$ das mulheres declararam-se casadas, ficando em segundo lugar, com $26,6 \%$ dos casos, as mulheres que conviviam com um companheiro fixo, numa relação consensual. A maioria, $54 \%$, tinha um ou dois filhos.

\section{Tabela I - Características sócio-demográficas das mulheres atendidas no Centro de Atendimento à Mulher de Londrina (PR), 2001}

\begin{tabular}{|l|c|c|}
\hline Características sócio-demográficas & N & $\%$ \\
\hline Faixa etária & & \\
\hline $10-19$ & 27 & 5,7 \\
\hline $20-29$ & 142 & 30,2 \\
\hline $30-39$ & 177 & 37,7 \\
\hline $40-49$ & 89 & 18,9 \\
\hline $50-59$ & 18 & 3,8 \\
\hline $60-69$ & 11 & 2,3 \\
\hline 70 e mais & 6 & 1,3 \\
\hline Estado Civil & & \\
\hline Casada & 222 & 47,2 \\
\hline Solteira & 50 & 10,6 \\
\hline Viúva & 17 & 3,6 \\
\hline Separada/divorciada & 56 & 11,9 \\
\hline União consensual & 125 & 26,6 \\
\hline Número de filhos & & \\
\hline Nenhum & 105 & 22,3 \\
\hline Um & 25 & 18,3 \\
\hline Dois & 111 & 23,6 \\
\hline Três & & 30,4 \\
\hline Quatro ou mais & & \\
\hline
\end{tabular}




\begin{tabular}{|c|c|c|}
\hline Características sócio-demográficas & $\mathrm{N}$ & $\%$ \\
\hline \multicolumn{3}{|l|}{ Escolaridade } \\
\hline Fundamental incompleto & 273 & 58,1 \\
\hline Fundamental completo & 55 & 11,7 \\
\hline Médio incompleto & 28 & 6,0 \\
\hline Médio completo & 60 & 12,8 \\
\hline Superior incompleto & 10 & 2,1 \\
\hline Superior completo & 6 & 1,3 \\
\hline Pós-graduada & 4 & 0,9 \\
\hline Alfabetizada & 24 & 5,1 \\
\hline Analfabeta & 10 & 2,1 \\
\hline \multicolumn{3}{|l|}{ Situação de Trabalho } \\
\hline Empregada* & 261 & 55,8 \\
\hline Desempregada & 59 & 12,6 \\
\hline Dona-de-casa & 134 & 28,6 \\
\hline Ignorado & 14 & 3,0 \\
\hline \multicolumn{3}{|l|}{ Renda individual } \\
\hline Até । salário mínimo & 94 & 20,0 \\
\hline I a I,99 salário mínimo & $12 \mid$ & 25,7 \\
\hline 2 ou 3 salários mínimos & 23 & 4,9 \\
\hline Mais de 3 salários mínimos & 31 & 6,6 \\
\hline Sem renda & 182 & 38,7 \\
\hline Ignorada & 19 & 4,0 \\
\hline
\end{tabular}

*Inclui empregadas no mercado formal, trabalhadoras informais e autônomas.

Quanto à escolaridade, prevaleceram as mulheres que não chegaram a concluir o ensino fundamental, correspondendo a $58,1 \%$ do universo. As que concluíram o ensino médio corresponderam a $12,8 \%$ e a taxa de analfabetismo foi de 2,1\%.

Ainda na tabela 1, observamos que, com relação à condição de trabalho, a maioria, 55,8\%, desenvolvia algum tipo de trabalho remunerado. Nessa proporção estão incluídas as empregadas no mercado formal, as trabalhadoras informais e as autônomas. Embora não tenha sido possível levantar as características com relação à situação de emprego no que diz respeito ao contrato de trabalho, pois esse tipo de informação não consta das fichas, acreditamos que muitas mulheres estivessem no mercado informal, devido aos tipos de atividade que declararam realizar, mais associadas à informalidade. Das que desenvolviam alguma atividade produtiva, 70,5\% estavam na prestação de serviços. Dessas, 36,4\% eram empregadas domésticas. Outras ocupações ligadas ao emprego doméstico, como lavadeira, cozinheira e faxineira, também apareceram com bastante freqüência, assim como as de vendedoras, manicuras e costureiras, atividades tradicionalmente femininas e de baixa remuneração.

Com relação à renda individual, quase a metade, $45,7 \%$, recebia menos de dois salários mínimos, e $38,7 \%$ das mulheres não possuíam renda própria. Uma parcela de $38 \%$ declarou-se chefe de família, valor bem maior que o observado no Estado do Paraná. De acordo com dados do Instituto Brasileiro de Geografia e Estatística (IBGE), relativos à Pesquisa Nacional por Amostras de Domicílio (PNAD) de 1999, 17,2\% das mulheres do Estado relataram ser chefes de família (Brasil, 1999).

Quanto à caracterização dos casos de violência, podemos observar na tabela 2 que prevalece a violência emocional, com $56,4 \%$ dos casos e, em segundo lugar, a violência física, com 32,1\%. Ressalta-se também que, dos 470 casos analisados, 41 referem-se a mulheres que vivenciaram tanto violência física quanto violência emocional. Em um caso houve sobreposição de violência física e sexual.

Na categoria de violência emocional, a tortura psicológica é a principal queixa, com 32,6\% do total de queixas apresentadas. A lesão corporal, caracterizada como violência física, é a segunda principal queixa, representando $25,5 \%$ dos casos.

Com relação ao ambiente em que ocorreu a violência, quase a totalidade dos casos $(97,4 \%)$ ocorreu no ambiente doméstico, resultado que se assemelha ao encontrado em outras pesquisas (Barsted, 1998; Diniz e cols., 1999; Deslandes e cols., 200o). Assim, o lar parece constituir-se no espaço privilegiado da violência contra a mulher, onde, resguardado da interferência de outras pessoas, o agressor conta ainda com o medo e a vergonha da pessoa agredida em denunciá-lo.

Os principais agressores são os atuais maridos ou companheiros, que, de acordo com a tabela 3, correspondem a 73,4\%. Agregando-se a esse tipo de agressor os namorados, ex-maridos ou ex-companheiros e exnamorados, a proporção desse conjunto, denominado de relação conjugal, perfaz 91,4\% das agressões, bastante superior ao encontrado por Deslandes e cols. (200o) entre mulheres atendidas em dois hospitais públicos na cidade do Rio de Janeiro (69,4\%). 
Tabela 2 - Caracterização dos casos atendidos no Centro de Atendimento à Mulher de Londrina (PR), conforme tipo de violência, queixa principal e ambiente em que ela ocorreu, 2001

\begin{tabular}{|c|c|c|}
\hline Características & $\mathrm{N}$ & $\%$ \\
\hline \multicolumn{3}{|l|}{ Tipo de violência } \\
\hline Física & 151 & 32,1 \\
\hline Emocional & 265 & 56,4 \\
\hline Sexual & II & 2,3 \\
\hline Física e emocional & 41 & 8,7 \\
\hline Física e sexual & 1 & 0,2 \\
\hline Outras & 1 & 0,2 \\
\hline \multicolumn{3}{|l|}{ Queixa principal } \\
\hline Tortura psicológica & 153 & 32,6 \\
\hline Negação de paternidade & 25 & 5,3 \\
\hline Abandono material & 57 & 12,1 \\
\hline Ameaça verbal & 66 & 14,0 \\
\hline Ameaça à integridade física & 5 & 1,1 \\
\hline Lesão corporal & 120 & 25,5 \\
\hline Infidelidade/adultério & 26 & 5,5 \\
\hline Atos destrutivos & 4 & 0,9 \\
\hline Estupro & 6 & 1,3 \\
\hline Assédio sexual & 3 & 0,6 \\
\hline Agressão verbal & 1 & 0,2 \\
\hline Várias & 1 & 0,2 \\
\hline Outras & 3 & 0,6 \\
\hline \multicolumn{3}{|c|}{ Ambiente onde ocorreu a violência } \\
\hline Ambiente doméstico & 458 & 97,4 \\
\hline Na rua & 4 & 0,9 \\
\hline No trabalho & 1 & 0,2 \\
\hline Outro local & 1 & 0,2 \\
\hline Ignorado & 6 & 1,3 \\
\hline
\end{tabular}

Compondo-se as variáveis idade da mulher e vínculo com o agressor, observa-se um aumento proporcional significativo da categoria "outro membro da família" como perpetrador da violência entre mulheres idosas. Se no total do universo essa categoria de agressor aparece em $6 \%$ dos casos, entre as mulheres com idade acima de 60 anos essa proporção sobe para 41,2\%, como pode ser observado na tabela 4 .

Embora mães e filhas também tenham sido citadas como agressoras em alguns casos, são os paren-
Tabela 3 - Caracterização dos casos atendidos no Centro de Atendimento à Mulher de Londrina (PR), conforme tipo de vínculo do agressor com a vítima, 2001

\begin{tabular}{|l|r|r|}
\hline Tipo de vínculo do agressor com a vítima & N & $\%$ \\
\hline Física & 151 & 32,1 \\
\hline Marido ou companheiro & 345 & 73,4 \\
\hline Ex-marido ou ex-companheiro & 57 & 12,1 \\
\hline Namorado & 1 & 0,2 \\
\hline Ex-namorado & 27 & 5,7 \\
\hline Outro membro da família & 28 & 6,0 \\
\hline Conhecido & 5 & 1,1 \\
\hline Desconhecido & 4 & 0,9 \\
\hline Ignorado & 3 & 0,6 \\
\hline Total & 470 & 100,0 \\
\hline
\end{tabular}

tes do sexo masculino que prevalecem na categoria "outro membro da família" e, no caso das mulheres idosas, os agressores são na maioria os filhos das vítimas. Analisando os relatos dessas mulheres registrados nas fichas de atendimento, observamos que, em geral, os argumentos usados pelas mães para justificarem a violência dos seus filhos contra elas é o uso de álcool ou outro tipo de droga por parte do agressor, como desencadeador dos atos de violência.

Quanto ao tempo em que vivenciam situações de violência, 33\% das mulheres vêm sofrendo agressões por períodos de até um ano. Uma proporção de 20,4\% dos casos refere-se a mulheres que sofrem agressões há mais de 10 anos. Foram registrados 13 casos de mulheres que relataram sofrer violência há mais de 30 anos. Este quadro reflete bem o processo de rotinização da violência (Organização das Nações Unidas, 1996). As agressões vão se tornando cada vez mais freqüentes, e as seqüelas, que podem ser visíveis como as resultantes da agressão física, ou emocionais, vão aos pouco se agravando.

A Delegacia da Mulher é o órgão que mais encaminha mulheres para o CAM, tendo sido responsável pelo encaminhamento de $50 \%$ dos casos. Em proporções bem menores aparecem ainda, como responsáveis pelo encaminhamento, outras usuárias do serviço, parentes, amigas/os ou conhecidas/os, profissionais ligados a serviços, tanto públicos quanto privados, das áreas de psicologia, assistência social, saúde e direito; 
Tabela 4 - Distribuição dos casos atendidos no Centro de Atendimento à Mulher de Londrina (PR), segundo faixa etária das vítimas e tipo de vínculo com o agressor, 2001

\begin{tabular}{|c|c|c|c|c|c|c|c|c|c|c|c|c|}
\hline \multirow[b]{3}{*}{ Vínculo com o agressor } & \multicolumn{12}{|c|}{ Faixa Etária } \\
\hline & \multicolumn{2}{|c|}{$10-19$} & \multicolumn{2}{|c|}{$20-29$} & \multicolumn{2}{|c|}{$30-39$} & \multicolumn{2}{|c|}{$40-49$} & \multicolumn{2}{|c|}{$50-59$} & \multicolumn{2}{|c|}{60 e mais } \\
\hline & $N$ & $\%$ & $\mathrm{~N}$ & $\%$ & $N$ & $\%$ & $\mathrm{~N}$ & $\%$ & $\mathrm{~N}$ & $\%$ & $\mathrm{~N}$ & $\%$ \\
\hline Marido ou companheiro & 15 & 55,6 & 105 & 73,9 & 142 & 80,2 & 63 & 70,8 & 12 & 66,6 & 8 & 47,0 \\
\hline Ex-marido ou ex-companheiro & 3 & 11,1 & 20 & 14,1 & 18 & 10,2 & 13 & 14,6 & 3 & 16,7 & - & - \\
\hline Namorado & 1 & 3,7 & - & - & - & - & - & - & - & - & - & - \\
\hline Ex-namorado & 3 & 11,1 & 12 & 8,5 & 9 & 5,1 & 3 & 3,4 & - & - & - & - \\
\hline Outro membro da família & 2 & 7,4 & 3 & 2,1 & 5 & 2,8 & 8 & 9,0 & 3 & 16,7 & 7 & 41,2 \\
\hline Conhecido & 1 & 3,7 & 1 & 0,7 & 1 & 0,6 & I & 1,1 & - & - & 1 & 5,9 \\
\hline Desconhecido & 1 & 3,7 & - & - & 2 & 1,1 & 1 & 1,1 & - & - & - & - \\
\hline Ignorado & 1 & 3,7 & 1 & 0,7 & - & - & - & - & - & - & 1 & 5,9 \\
\hline Total & 27 & 100,0 & 142 & 100,0 & 177 & 100,0 & 89 & 100,0 & 18 & 100,0 & 17 & 100,0 \\
\hline
\end{tabular}

vereadores/as e conselheiros/as tutelares. Embora representando um número muito pequeno, aparecem ainda algumas mulheres que procuraram o CAM por conta própria, tendo tomado conhecimento do serviço por meio de divulgação feita nos veículos de comunicação locais ou por meio de palestras e oficinas que são realizadas esporadicamente pelos profissionais do CAM em escolas, associações de moradores e outros espaços públicos, para debater o assunto com a comunidade e divulgar o serviço.

Os serviços de saúde - prioritariamente hospitais e unidades básicas - aparecem como responsáveis por apenas 3,6\% dos encaminhamentos. Num estudo realizado em Belo Horizonte, englobando usuárias de dois serviços de apoio à mulher que realizam trabalho similar ao CAM, verificou-se que $80 \%$ dos casos atendidos provinham de instituições públicas, sendo $64 \%$ de serviços de saúde (Alves e Coura Filho, 2001). Em comparação com esse estudo, a proporção de encaminhamentos oriundos dos serviços de saúde, em Londrina, é muito baixa.

Admitindo que as mulheres que sofrem violência têm maior probabilidade de apresentarem problemas de saúde, logo se deve supor que elas procuram com mais freqüência os serviços de saúde (Schraiber e D’Oliveira, 1999). Nesse caso, esses deveriam ser vistos como estratégicos, no que diz respeito às ações de prevenção da violência contra a mulher. 0 baixo índi- ce de encaminhamentos de casos para o CAM por parte dos serviços de saúde evidencia, talvez, a pouca integração que há entre esses serviços, no município de Londrina.

Gomes e cols. (2002), em pesquisa sobre a abordagem dos maus-tratos contra crianças e adolescentes em uma unidade pública de saúde do Rio de Janeiro, chamam a atenção para o fato de que esta questão ainda não foi incorporada nos currículos de graduação, deixando uma lacuna na formação desses profissionais. Os autores apontam um certo despreparo dos profissionais de saúde para lidar com a questão, comprometendo a identificação dos casos e a realização de atendimentos e de encaminhamentos adequados. Acreditamos que no caso da violência contra a mulher, guardadas as devidas proporções, esse mesmo despreparo dificulte uma intervenção mais efetiva dos profissionais de saúde quanto ao reconhecimento dos casos de violência, ao atendimento e ao encaminhamento das mulheres aos demais serviços de apoio nessa área.

Nesse contexto, Schraiber e cols. (2003) chamam a atenção para o silêncio e a invisibilidade que envolvem a questão da violência contra a mulher, destacando a natureza do problema situado no âmbito da vida privada e das relações familiares. Existe uma dificuldade em falar e tratar do assunto, tanto por parte das mulheres agredidas quanto por parte dos profissio- 
nais da saúde. Por trás desse silêncio estão duas questões importantes: o não reconhecimento de que a violência contra a mulher é problema de atenção à saúde e a tendência de se usar a linguagem do adoecimento, o que dificulta a comunicação entre os profissionais da saúde e as usuárias dos serviços.

Não obstante a proliferação de estudos que têm demonstrado a dimensão, a complexidade e a gravidade da violência contra a mulher quanto aos impactos à sua saúde, a questão ainda não é plenamente reconhecida enquanto problema de saúde pública. Sendo assim, faz-se necessária a ampliação desse debate, que deve partir de uma revisão dos valores que norteiam as práticas de intervenção na área da saúde, visando o estabelecimento de novas formas de interação e, conseqüentemente, de intervenções mais resolutivas.

\section{Considerações Finais}

A violência doméstica praticada por maridos ou companheiros apresenta grande incidência. Nestes casos, os episódios de agressão costumam ser repetitivos, o que implica maior impacto à saúde das mulheres (Schraiber e D’Oliveira, 1999; Schraiber e cols., 2002). A violência emocional, que prevaleceu em relação às outras formas de violência, apesar de não deixar marcas, é motivo de sofrimento e causa de inúmeras doenças, cujos sintomas muitas vezes não são percebidos pelos profissionais de saúde (Grossi, 1996; Diniz e cols., 1999).

Embora nesta investigação o universo analisado seja composto basicamente por mulheres de camadas de baixa renda, sabe-se que a dependência econômica não é o único fator que leva as mulheres a permanecerem convivendo com homens agressores. Para entender os determinantes dessa situação é importante considerar também a dependência emocional (Saffioti, 1997) e os aspectos culturais associados à construção social dos papéis femininos e masculinos que determinam a forma como se estabelecem as relações de dominação e submissão entre os gêneros (Gregori, 1993; Meneghel e cols., 200o).

Romper com o ciclo da violência é extremamente difícil para grande parte das mulheres que vivem essa situação, fato comprovado na presente pesquisa, que evidenciou um número elevado de mulheres vivendo em situação de violência há mais de um ano. Mesmo as mulheres que tomam a atitude de denunciar seus companheiros agressores, muitas vezes, acabam desistindo de manter a denúncia. Diante das promessas do companheiro de não mais agredi-la, da falta de perspectiva e de condições materiais para um recomeço, da vergonha e da falta de apoio da família e da sociedade, acabam acreditando numa possível reconciliação, o que acaba por gerar o processo chamado de "rotinização da violência”.

Apesar dos avanços obtidos em termos de reconhecimento, no âmbito do poder público, da problemática da violência contra a mulher enquanto questão a ser tratada com políticas públicas específicas, as intervenções ainda estão mais associadas às áreas de segurança pública e assistência social.

$\mathrm{Na}$ área da saúde, embora o tema venha ganhando espaço em estudos e pesquisas voltados à questão, ainda são poucos os serviços organizados para atender aos casos de violência. Em primeiro lugar, um dos obstáculos à implementação de ações efetivas nessa área diz respeito à ausência de estatísticas capazes de dimensionar a incidência da violência contra a mulher. Os profissionais da saúde não contam com instrumentos que os orientem no reconhecimento e no registro dos casos atendidos nos serviços de saúde e não estão preparados para orientarem as mulheres sobre seus direitos e para encaminhá-las aos demais serviços de apoio existentes (Fontana e Santos, 2001). Por outro lado, esses profissionais têm dificuldades em reconhecer a violência como problema de saúde, além de não estarem preparados para uma efetiva comunicação com as mulheres que vivenciam essa situação (Schraiber e cols., 2003).

A complexidade que envolve a questão da violência contra a mulher exige ações capazes de dar conta das inúmeras demandas apresentadas, o que implica a necessidade de articulação entre diferentes áreas de conhecimento e de atuação. Assim, os serviços de atendimento às mulheres em situação de violência são de fundamental importância para o enfrentamento desse problema, sendo imprescindível que estes estejam articulados com os serviços de saúde no desenvolvimento de ações preventivas e assistenciais, na perspectiva da atenção integral à mulher. 


\section{Referências}

ALVES, A. M.; COURA FILHO, P. Avaliação das ações de atenção às mulheres sob violência no espaço familiar atendidas no Centro de Apoio à Mulher (Belo Horizonte), entre 1996 e 1998. Revista Ciência \& Saúde Coletiva, Rio de Janeiro, v. 6, n.1, p. 243257, 2001.

BARSTED, L. de A. L. Uma vida sem violência é um direito nosso: propostas de ação contra a violência intrafamiliar no Brasil. Brasília: Comitê Interagencial de Gênero/ONU/Secretaria Nacional dos Direitos Humanos/Ministério da Justiça, Brasília, 1998.

BRASIL. Ministério da Justiça . Conselho Nacional dos Direitos da Mulher. Indicadores de gênero. 1999. Disponível em: <www.mj.gov.br/sedh/cndm/ genero/demografia/RG_caroo6/1999.htm>. Acesso em 3 jun. 2002.

CAMARGO, M. Violência e saúde: ampliando políticas públicas. Jornal da RedeSaúde, São Paulo, n. 22, nov., 20oo. Disponível em: <http://www.redesaude.org.br/ jornal/html/body_jr22-marcia-camargo.html.>. Acesso em 1 ago. 2001.

CENTERS FOR DISEASE PREVENTION AND CONTROL. Building data systems for monitoring and responding to violence against women: recommendations from a workshop. [mimeo]

Morbidity and Mortality Weekly Report, Atlanta (EUA), v. 49, n. RR-11, p. 1-16, Oct. 2000.

DESLANDES, S. F.; GOMES, R.; SILVA, C. M. F. P. da. Caracterização dos casos de violência doméstica contra a mulher atendidos em dois hospitais públicos do Rio de Janeiro. Cadernos de Saúde Pública, Rio de Janeiro, v.16, n.1, p. 129-137, jan-mar, 2000.

DINIZ, N. M. F. et al. Mulher, saúde e violência: o espaço público e o privado. O Mundo da Saúde, São Paulo, v. 23, n.2, p. 106-112, 1999.

FONTANA, M; SANTOS, S. F. dos. Violência contra a mulher. In: REDESAUDE. Saúde da mulher e direitos reprodutivos: dossiês. São Paulo: Rede Nacional Feminista de Saúde e Direitos Reprodutivos, 2001. p.101-128.
GOMES, R. et al. A abordagem dos maus-tratos contra a criança e o adolescente em uma unidade pública de saúde. Ciência \& Saúde Coletiva, Rio de Janeiro, v.7, n.2, p. 275-283, 2002.

GREGORI, M. F. Cenas e queixas: um estudo sobre mulheres, relações violentas e a prática feminista. Rio de Janeiro: Paz e Terra. São Paulo: ANPOCS, 1993.

GROSSI, K. Violência contra a mulher: implicações para os profissionais de saúde. In: LOPES, M. J. M.; MEYER, D. E.; WALDOW, V. R. (Orgs.) Gênero e Saúde. Porto Alegre: Artes Médicas, 1996. p.133-149.

GUERRA, C. Ei tá violência conjugal e familiar nossa de cada dia - dados levantados nos prontuários do S.O.S. Mulher/Família de Uberlândia. Gênero em Pesquisa, Uberlândia, n. 15, p.4-5, 2000.

GUERRA, C. Violência e poder nas relações de gênero - as cenas. Caderno Espaço Feminino, Uberlândia, v. 4, n. 4/5, p. 5-27, jan./dez. 1997.

KLEVENS, J. Violência física contra la mujer em Santa Fe de Bogotá: prevalencia y fatores asociados. Revista Panamericana de Salud Pública, Washington-DC, v. 9, n. 2, p. 78-83, 2001.

LEMES, V. S. Levantamento parcial de dados sobre a violência conjugal e familiar em Uberlândia/2001. Gênero em pesquisa, Uberlândia, n. 18, p. 35-45, 2002.

MENEGHEL, S. N. et al. Mulheres cuidando de mulheres: um estudo sobre a Casa de Apoio Viva Maria, Porto Alegre, Rio Grande do Sul, Brasil. Cadernos de Saúde Pública, Rio de Janeiro, v. 16, n. 3, p. 747757, jul./set., 2000.

ORGANIZAÇÃO DAS NAÇÕES UNIDAS. IV Conferência Mundial Sobre a Mulher. Rio de Janeiro: ONU CNDM - FIOCRUZ, 1996.

PREFEITURA MUNICIPAL DE LONDRINA. Secretaria Especial da Mulher. Violência Contra a Mulher: informação e orientação. Londrina, 1998.

PREFEITURA MUNICIPAL DE LONDRINA. Secretaria Especial da Mulher. Seminário Combate à Violência Contra a Mulher: construindo redes e parcerias. Londrina, 2000. 
SAFFIOTI, H.; ALMEIDA, S. de S. Violência de gênero: poder e impotência. Rio de Janeiro: Revinter, 1995.

SAFFIOTI, H. Violência doméstica ou a lógica do galinheiro. In: KUPSTAS, M. (Org.) Violência em debate. São Paulo: Moderna, 1997. p. 39-57.

SANTANA, V. Um novo começo: a experiência da Casa do Caminho, a prática de acolhimento das mulheres vítimas da violência em Fortaleza. In: FUJIWARA, L.M., ALESSIO, N.L.N., FARAH, M.F.S. (Org.). 20 Experiências de gestão pública e cidadania. São Paulo: Programa Gestão Pública e Cidadania - Fundação Getúlio Vargas, 1999. p. 45-55.

SCHRAIBER, L. B.; D'OLIVEIRA, A. F. L. P. Violência contra mulheres: interfaces com a saúde. Interface - Comunicação, Saúde e Educação, Botucatu, v. 3 , n. 5, p. 11-26, ago. 1999.
SCHRAIBER, L. B. et al. A. Violência contra a mulher: estudo em uma unidade de atenção primária à saúde. Revista de Saúde Pública, São Paulo, v. 36, n. 4, p. 470-477, jul/ago. 2002.

SCHRAIBER, L. B. et al.. Violência vivida: a dor que não tem nome. Interface - Comunicação, Saúde e Educação, Botucatu, v. 6, n. 10, p. 41-54, fev. 2003.

VACCARI. V.L. Projeto cidadania e gênero: superando a violência contra a mulher. Gênero em Pesquisa, Uberlândia. n. 17, p. 2-8, 2001.

WORLD HEALTH ORGANIZATION. World report on violence and health E-Book. Geneva: World Health Organization, 2002. Disponível em: http:// www.who.int/violence_injury_prevention/ violence/world_report/wrvheng/en/print.html Acesso em: 30 jul. 2004. 